\title{
Subintimal intraplaque haemorrhage prior to aortic plaque rupture: 2-year angioscopic follow-up
}

\author{
Sei Komatsu, Satoru Takahashi, Mitsuhiko Takewa, Kazuhisa Kodama
}

Cardiovascular Center, Osaka Gyoumeikan Hospital, Osaka, Japan

\section{Correspondence to Dr Sei Komatsu, plaquemap@yahoo.co.jp}

Accepted 17 March 2018

\section{DESCRIPTION}

An 81-year-old man was referred to our hospital for intermittent claudication for 2 months. He had a history of hypertension, dyslipidaemia, renal insufficiency and percutaneous coronary intervention of the left circumflex coronary artery 3 years ago. Non-obstructive angioscopy (NOA) of the aorta had been performed to evaluate aortic atherosclerosis 2 years earlier. ${ }^{1}$ At the suprarenal abdominal artery, a partially peeled section of the intima was detected via NOA using the caterpillar method ${ }^{2}$ (figure 1A). At this site, blood flow filled the space between the intima and the peeled surface with pulsation (video 1). This was thought to be a subintimal intraplaque haemorrhage. CT angiography did not demonstrate any sign of aortic dissection at the corresponding area except for intimal thickening (figure $1 \mathrm{~B}$ ). Since the last catheterisation, the patient has not experienced chest or back pain. He has experienced intermittent claudication from the progression of right common iliac artery stenosis,
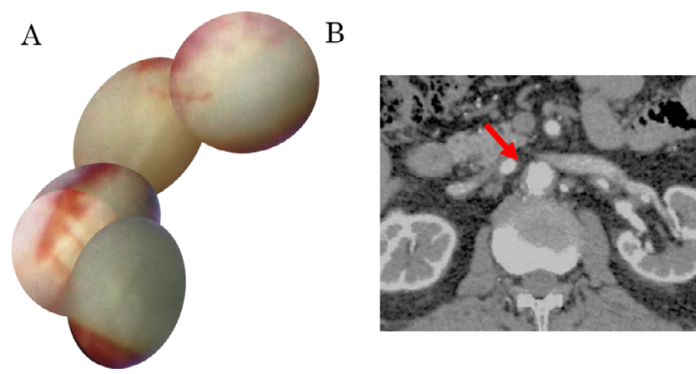

Figure 1 The subintimal haemorrhage at the suprarenal abdominal artery. (A) Angioscopic image. The intima was partially peeled. At this site, blood flow filled the space between the intima and the peeled surface with pulsation. (B) Axial CT image of the corresponding area. The aorta did not show dilatation. Hazy intimal thickening was identified.

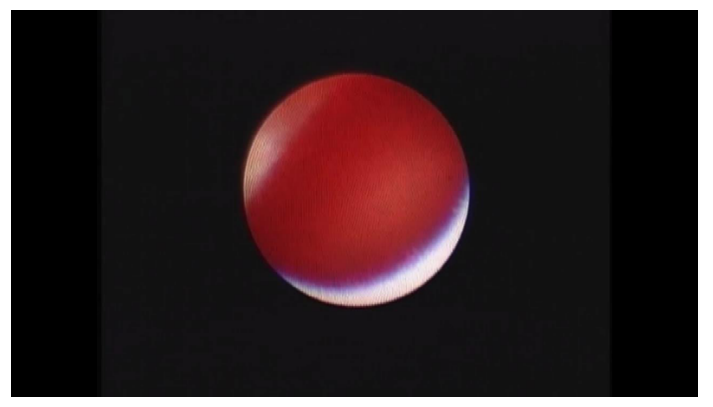

Video 1 The subintimal haemorrhage from the peeled intima at the suprarenal abdominal artery as seen on non-obstructive angioscopy

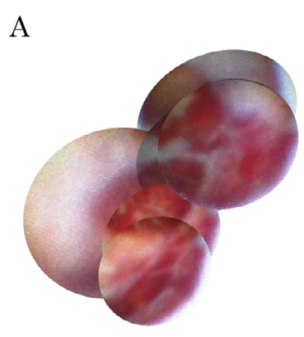

B

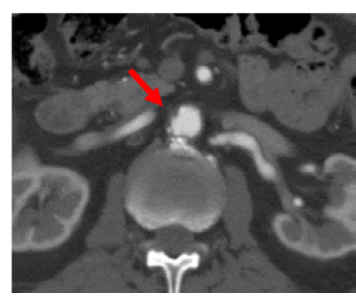

Figure 2 A large cavity 2 years later at the site of the subintimal haemorrhage. (A) Angioscopic image. A larger cavity with a complicated structure and frames covered with red thrombi were seen. (B) Axial CT image of the corresponding area. Slightly progressed hazy intimal thickening was found without any sign of aortic dissection or obvious penetrating atherosclerotic ulcer.

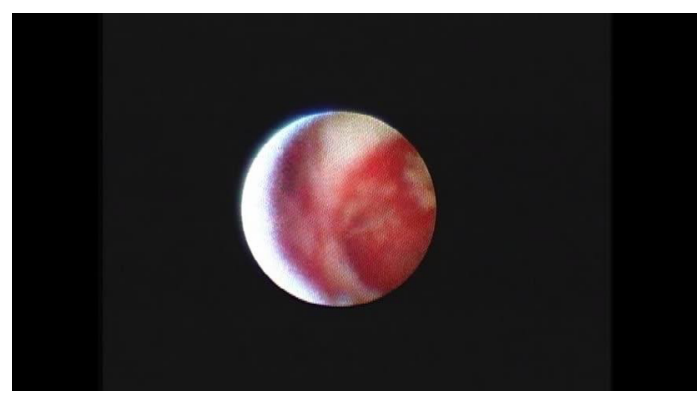

Video 2 A large cavity 2 years later at the site of the subintimal haemorrhage as seen on non-obstructive angioscopy

apart from the lesion. Angioscopically, the lesion cavity has become larger, the structure has become complicated, and areas covered with red thrombi have been exposed (figure 2A, video 2). CT angiography demonstrated a slight progression of intimal thickening, but still no sign of aortic dissection (figure 2B). We presumed that NOA demonstrated

Learning points

- A subintimal intraplaque haemorrhage may be the beginning of aortic plaque rupture.

- Angioscopy may detect the fragility of an asymptomatic aorta, such as a subintimal intraplaque haemorrhage or an aortic plaque rupture.

- Long-term follow-up and more evidence are needed to clarify the significance of a subintimal intraplaque haemorrhage and aortic plaque rupture. 
the beginning of plaque rupture with a subintimal haemorrhage and cavity and showed disrupted plaque 2 years later.

Contributors SK wrote the first version of the manuscript. MT and ST performed the supervision of the manuscript, gave expert opinion, looked for the images and corrected the final version. KK supervised all the process, gave expert opinion and gave final approval for the version of the manuscript.

Funding This research received no specific grant from any funding agency in the public, commercial or not-for-profit sectors.

Competing interests None declared.

Patient consent Obtained.
Provenance and peer review Not commissioned; externally peer reviewed.

(c) BMJ Publishing Group Ltd (unless otherwise stated in the text of the article) 2018. All rights reserved. No commercial use is permitted unless otherwise expressly granted.

\section{REFERENCES}

1 Komatsu S, Ohara T, Takahashi S, et al. Early detection of vulnerable atherosclerotic plaque for risk reduction of acute aortic rupture and thromboemboli and atheroemboli using non-obstructive angioscopy. Circ $J$ 2015;79:742-50.

2 Komatsu S, Takahashi S, Ohara T, et al. Aortic valve stenosis and atheromatous ascending aorta. Intern Med 2017;56:2685-6.

Copyright 2018 BMJ Publishing Group. All rights reserved. For permission to reuse any of this content visit

http://group.bmj.com/group/rights-licensing/permissions.

BMJ Case Report Fellows may re-use this article for personal use and teaching without any further permission.

Become a Fellow of BMJ Case Reports today and you can:

- Submit as many cases as you like

- Enjoy fast sympathetic peer review and rapid publication of accepted articles

- Access all the published articles

Re-use any of the published material for personal use and teaching without further permission

For information on Institutional Fellowships contact consortiasales@bmjgroup.com

Visit casereports.bmj.com for more articles like this and to become a Fellow 